\title{
THE SURFACE GLOSS AND MICRO-HARDNESS OF TWO RECENT TOOTH COLORED RESTORATIVE MATERIALS AFTER IN-OFFICE BLEACHING
}

\author{
Hebatallah M. Taher* and Eman A. Abouauf**
}

\begin{abstract}
The aim of this study was to compare the surface gloss and micro hardness of two types of tooth colored restorative materials (Ketac Universal Aplicap glass ionomer and Vertise Flow self adhesive resin composite), after the exposure to in-office bleaching agent.

Materials and methods: A total of twenty discs were divided into two equal groups of two tested restorative materials; Ketac Universal Aplicap Glass ionomer and Vertise flow self adhesive flowable resin composite. In-office teeth whitening gel was applied on each specimen surface. Measurement of the surface gloss and micro-hardness was done to all the specimens before and after the bleaching procedure.
\end{abstract}

Results: The surface gloss of both tested materials showed lower mean value after bleaching than before bleaching and was statistically significant. On the other hand, the micro-hardness of both tested materials showed lower mean value after bleaching than before bleaching and was statistically significant.

Conclusion: the surface configuration and micro-hardness of both tested materials were negatively influenced when subjected to in-office bleaching.

\section{INTRODUCTION}

Many esthetic restorations are introduced to the dental market; manufacturers are expressing the excellence of many newly introduced products in terms of color stability and superior surface finish. This competition might put the clinician in a puzzle seeking perfection and excellence during the restoration of hard dental tissue defect.
Direct resin composite is one of the most popular tooth colored options restoring small and medium size cavities. Yet, the etching and bonding procedures might be considered a technique sensitive step for some clinicians in addition to the time factor. For these reasons, some manufacturers introduced the self-adhesive resin composite material to overcome such problem. Moreover, flowable resin composites

\footnotetext{
* Assistant Professor of conservative Dentistry, Faculty of Dentistry Cairo University and Modern Sciences and Art in Egypt. ** Lecturer of Conservative Dentistry, Faculty of Dentistry, Cairo University, Egypt.
} 
offered the merit of easier handling properties due to the lower viscosity (Xie et al, 2008).

Also, a recently introduced glass ionomer restorative material (directly applied in the prepared cavity) with no need to apply a protective coating, could be a temptation for the clinicians to use more widely. This product was promised to deliver physical and mechanical properties higher than conventional GI as it required regular protective coating as told by the manufacturer.(3M, ESPE, USA).

The community being influenced by the perfect white smile in the media is asking for whiter and more perfect smile. This was expressed by the public demanding teeth whitening treatments. Professionally applied tooth whitening products are frequently used in the dental office and became a daily routine. Such products which contain peroxides might influence the color behavior of the tooth colored restorations or even lead to its deterioration (Yu et al, 2008) (Rosentritt et al, 2005).

Sometimes, an interaction between the restorative material and the bleaching agent might induce an obvious color change, thus it could end up in a color mismatch between the tooth structure and the restoration which is considered a major esthetic failure (Canay and Cehreli, 2003).

So, it was important to investigate the influence of tooth whitening products on the recently introduced self-adhesive flowable resin composite (Vertise flow) and on the recently introduced Glass ionomer (Ketac Universal) as regards the surface gloss, microhardness.

\section{MATERIALS AND METHODS}

Detailed description of the selected materials as mentioned by the manufacturers is presented in table (1).

\section{Specimens grouping}

A total of twenty discs $(10 \mathrm{~mm}$ in diameter and $2 \mathrm{~mm}$ thickness) were divided into two groups (10 discs each) according to the restorative material used ; Group I: Ketac Universal Aplicap Glass ionomer discs and Group II: Vertise flow self adhesive flowable resin composite discs.

TABLE (1): Materials used in the study

\begin{tabular}{|c|c|c|c|}
\hline Material used & Commercial name & Composition & Manufacturer \\
\hline $\begin{array}{l}\text { Conventional glass ionomer } \\
\text { restorative material } \\
\text { with a self-cure (acid-base) } \\
\text { mechanism }\end{array}$ & $\begin{array}{c}\text { Ketac }^{\mathrm{TM}} \\
\text { Universal Aplicap }\end{array}$ & $\begin{array}{c}\text { Powder: Oxide glass }>95 \mathrm{Wt} \% \text {. } \\
\text { Liquid: Water (40-60 Wt. \%, } \\
\text { Copolymer of acrylic acid - maleic } \\
\text { acid (30-50 Wt. \%, Tartaric acid (1-10 } \\
\text { Wt.) and Benzoic acid (<0.2 Wt. \%). }\end{array}$ & $\begin{array}{c}\text { 3M ESPE, Dental } \\
\text { Products, } \\
\text { St. Paul, } \\
\text { MN,USA }\end{array}$ \\
\hline $\begin{array}{c}\text { Self-adhesive flowable resin } \\
\text { composite }\end{array}$ & Vertise Flow & $\begin{array}{l}\text { GPDM; HEMA, prepolymerzed filler } \\
(20 \mu \mathrm{m}) \text {, barium glass filler }(0.7-1 \mu \mathrm{m}) \text {, } \\
\text { nano-sized colloidal silica }(10-40 \mathrm{~nm}) \text {, } \\
\text { nano-sized Ytterbium fluoride }(40 \mathrm{~nm}) \\
\text { Zinc-oxide pH: } 1.9 \\
70 \text { wt } \% \text { filler content. }\end{array}$ & Kerr, Orange, CA, USA \\
\hline In-office bleaching gel & $\begin{array}{l}\text { Dash In-Office } \\
\text { Teeth Whitening }\end{array}$ & $30 \%$ hydrogen peroxide gel $2.9 \mathrm{~g}$ & $\begin{array}{l}\text { Discus Dental, LLC Culver } \\
\text { City, CA } 90232 \text { USA USA: } \\
\text { (800) } 422-9448\end{array}$ \\
\hline
\end{tabular}




\section{Glass Ionomer specimen preparation}

The teflon mold with a central hole $(10 \mathrm{~mm}$ in diameter and $2 \mathrm{~mm}$ in thickness) was used. The mold was placed over a microscopic glass slide topped with a Mylar strip. Ketac Universal Aplicap glass ionomer capsules were mixed by the RotoMix apparatus (3M-ESPE, Seefeld, Germany), according to the manufacturer instructions. The mold hole was filled with the GI restorative material and instantly, the surface of the material was covered by a Mylar strip and pressed (weight of $200 \mathrm{~g}$ ) with another microscope slide to obtain a smooth and flat surface. Seven minutes later, the glass slide and matrix were removed.

\section{Resin composite specimen preparation}

The same teflon mold was utilized to obtain standardized discs $(10 \mathrm{~mm}$ in diameter and $2 \mathrm{~mm}$ in thickness) and was placed over a microscopic glass slide topped with a Mylar strip. Vertise flow self adhesive flowable resin composite was used according to manufacturer instructions; a thin layer of the material $(0.5 \mathrm{~mm})$ was applied into the hole using the brush supplied by the manufacturer, light cured for 15-20 seconds then a final layer was applied, covered with a Mylar strip and pressed (weight of $200 \mathrm{~g}$ ) with another microscope slide to obtain a smooth and flat surface, finally light cured for 20 seconds at zero distance from the surface

A sequence of specimens was specified using a computer generated random sequence table (randomn.org) and was conducted by another author. In order to apply the allocation sequence, numbered containers were used and the sequence was masked during the investigation. The operator was blinded and unaware of the type of materials tested during surface gloss and micro-hardness measurements.

\section{Surface gloss measurements}

The surface gloss of resin composite and glass ionomer specimens were measured before and after bleaching using gloss meter (HORIBA, Gloss checker, IG 331, Japan.) with an oval measurement area of $3 \times 6 \mathrm{~mm}$ for angle $60^{\circ}$. The device was calibrated and for replication of measurements a custom - made mold with a centralized hole space of the same size of the Teflon mold was used.

\section{Vickers micro-hardness measurement}

Surface micro-hardness of the specimens were determined before and after bleaching using digital display Vickers micro-hardness tester (Model HMV-2 series, Shimadzu micro hardness tester, Kyoto, Japan) with a Vickers diamond indenter and (10X and 40X ) objective lenses. Vickers microhardness testing was done for the surface under a load of $200 \mathrm{~g}$ for 15 seconds. Three indentations were made apart from each other. The indentations were done approximately in the center of each specimen. After adjustment of the HV tester, the specimen was placed on the tested anvil, and then the object lens was rotated to be with the axis of the test anvil. The elevating handle was turned to raise the test anvil until the surface of the specimen can be seen clearly through the eyepiece. The handle was turned to rotate the axis of the indenter to align with the axis of the test anvil. Then, the start button was pressed to begin the testing process. The HV diamond tester automatically carries out the test process; loading, dwelling and unloading. After the test force was unloaded the handle was turned until the axis of the object lens was aligned with that of the test anvil. The indentation was observed through the eyepiece a nd the length of the two diagonals was measured with micrometer and shown on the LCD screen automatically. For each indentation, the two diagonals (the horizontal and the vertical axis) were measured and the mean value of them was taken and converted into Vickers hardness number. The hardness value was obtained by the following formula: $\mathrm{HV}=0.1891 \mathrm{~F} / \mathrm{d}^{2}$

$\mathrm{HV}$ : Vickers hardness $\left(\mathrm{kgf} / \mathrm{mm}^{2}\right)$

F: Test load applied to the indenter (kgf)

$\mathrm{D}$ : average of the two indentation diagonal lengths (mm) 
The mean value for each of the three recorded VHN was calculated and considered as the mean VHN for each specimen.

\section{Bleaching gel application}

Dash In-Office Teeth Whitening gel was applied on the specimen surface, using flocked tip and left for 15 minutes. The cycle was repeated three times each for 15 mins according to the manufacturer instructions. After each cycle the gel was wiped off the specimen surface with clean gauze. Finally, distilled water was used to rinse each specimen for 120s. Afterword, each specimen was blotted dry using a filter paper

All the tested specimens were subjected to measurement of the surface gloss and microhardness.

\section{Statistical analysis:}

The mean and standard deviation values were calculated for each group in each test. Data were explored for normality using Kolmogorov-Smirnov and Shapiro-Wilk tests, data showed parametric (normal) distribution. Independent sample t-test was used to compare between two groups in nonrelated samples. Paired wise sample t-test was used to compare between two groups in related samples. The significance level was set at $\mathrm{P} \leq 0.05$. Statistical analysis was performed with IBM ${ }^{\circledR}$ SPSS ${ }^{\circledR}$ Statistics Version 20 for Windows.

\section{RESULTS}

\section{Surface Gloss:}

1) The influence of the bleaching procedure on the surface gloss of each tested restorative material:

Table (2), figure (1) representing both tested materials (Ketac Universal Aplicap and Vertise Flow) which showed a statistically significant difference between before and after the bleaching procedures. For both tested materials the highest mean values were recorded before the bleaching procedure (mean $=39.57, \mathrm{SD}=8.27$ and mean= 45.78, $\mathrm{SD}=9.64$ respectively), while the lowest mean values were recorded after the bleaching (mean $=35.34, \mathrm{SD}=8.51$ and mean $=35.4, \mathrm{SD}=7.85$ respectively) where $(p<0.001)$.

TABLE (2): The mean, standard deviation (SD) of the surface gloss before and after bleaching procedures for the two tested materials.

\begin{tabular}{|c|c|c|c|c|}
\hline \multirow{2}{*}{ Variables } & \multicolumn{4}{|c|}{ Gloss } \\
\cline { 2 - 5 } & \multicolumn{2}{|c|}{ Vertise Flow } & \multicolumn{2}{c|}{ Ketac Univeral Aplicap } \\
\cline { 2 - 5 } & Mean & SD & Mean & SD \\
\hline Before & 45.78 & 9.64 & 39.57 & 8.27 \\
\hline After & 35.4 & 7.85 & 35.34 & 8.51 \\
\hline p-value & \multicolumn{2}{|c|}{$<\mathbf{0 . 0 0 1 *}$} & \multicolumn{2}{|c|}{$<\mathbf{0 . 0 0 1 *}$} \\
\hline
\end{tabular}

*; significant $(p<0.05) n s ;$ non-significant $(p>0.05)$

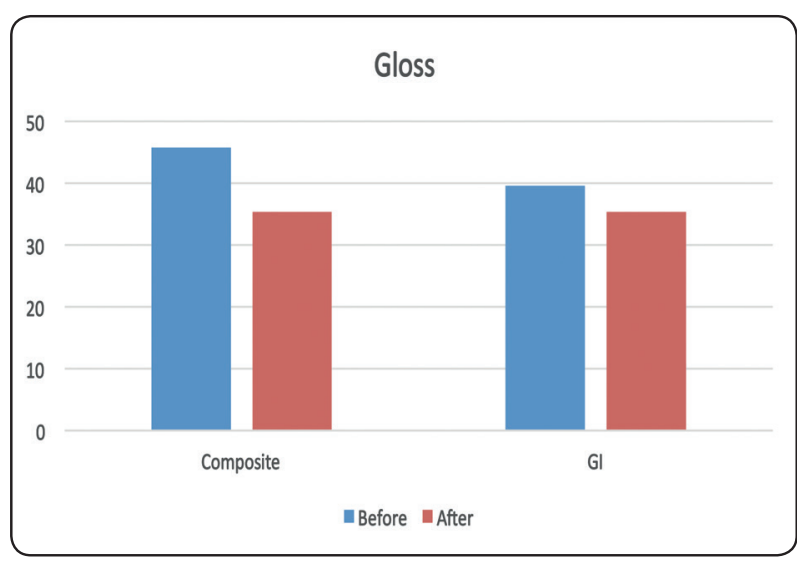

Fig. (1): Bar chart representing surface gloss before and after bleaching procedures for the two tested materials

\section{2) Comparing the percentage of change in} the surface gloss of the tested restorative materials due to the bleaching procedure

A statistically significant difference was found between both tested restorative materials. (Table: 3 and fig: 2). The highest mean value was recorded in Ketac Universal Aplicap (mean $=10.38, \mathrm{SD}=2.8$ ), 
while the lowest mean value was found in Vertise Flow (mean $=4.24, \mathrm{SD}=1.4)$ where $(p<0.001)$.

TABLE (3): The mean, standard deviation (SD) and percentage of change of the surface gloss in both test materials under the influence of the bleaching procedure.

\begin{tabular}{|l|c|c|c|}
\hline \multirow{2}{*}{\multicolumn{1}{|c|}{ Variables }} & \multicolumn{3}{|c|}{ Gloss } \\
\cline { 2 - 4 } & Mean & SD & $\%$ \\
\hline Vertise Flow & 4.24 & 1.47 & $11.22 \%$ \\
\hline Ketac Universal Aplicap & 10.38 & 2.8 & $22.75 \%$ \\
\hline p-value & \multicolumn{3}{|c|}{$<\mathbf{0 . 0 0 1 *}$} \\
\hline
\end{tabular}

*; significant $(p<0.05)$ ns; non-significant $(p>0.05)$

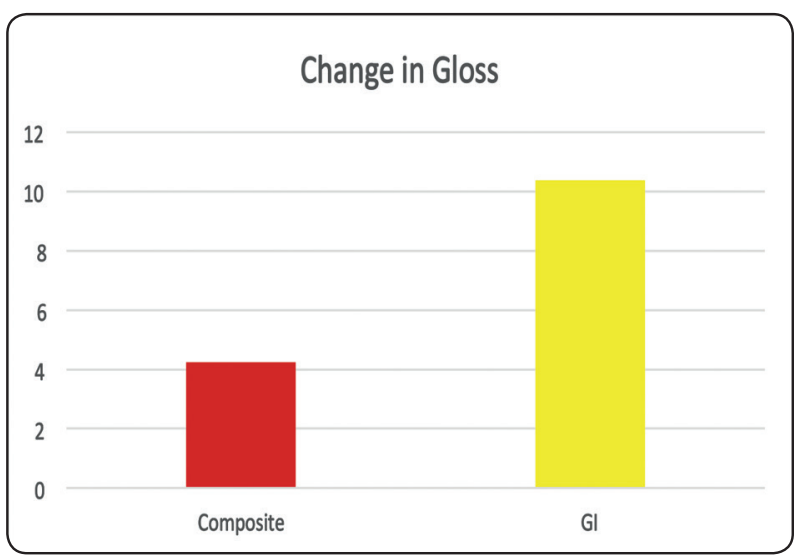

Fig. (2): Bar chart representing the change of the surface glosses for both test groups under the influence of the bleaching procedure.

\section{Micro-hardness}

1) The influence of the bleaching procedure on the micro-hardness of each tested restorative material:

Table (4) and figure (3) representing both tested materials (Ketac Universal Aplicap and Vertise Flow) showed a statistically significant difference between before and after the bleaching procedures. For both tested materials the highest mean values were recorded before the bleaching procedure (mean $=48.93, \mathrm{SD}=3.72$ and mean $=13.86, \mathrm{SD}=0.84$ respectively), while the lowest mean values were recorded after the bleaching (mean $=42.77$, $\mathrm{SD}=2.59$ and mean $=12.76, \mathrm{SD}=0.83$ respectively) where $(p<0.001)$.

TABLE (4): The mean, standard deviation (SD) of micro-hardness before and after bleaching procedures for the two tested materials.

\begin{tabular}{|c|c|c|c|c|}
\hline \multirow{3}{*}{ Variables } & \multicolumn{4}{|c|}{ Microhardness } \\
\hline & \multicolumn{2}{|c|}{ Vertise Flow } & \multicolumn{2}{|c|}{ Ketac Universal Aplicap } \\
\hline & Mean & SD & Mean & SD \\
\hline Before & 13.86 & 0.84 & 48.93 & 3.72 \\
\hline After & 12.76 & 0.83 & 42.77 & 2.59 \\
\hline p-value & \multicolumn{2}{|c|}{$<0.001 *$} & \multicolumn{2}{|c|}{$<0.001 *$} \\
\hline
\end{tabular}

*; significant $(p<0.05)$ ns; non-significant $(p>0.05)$

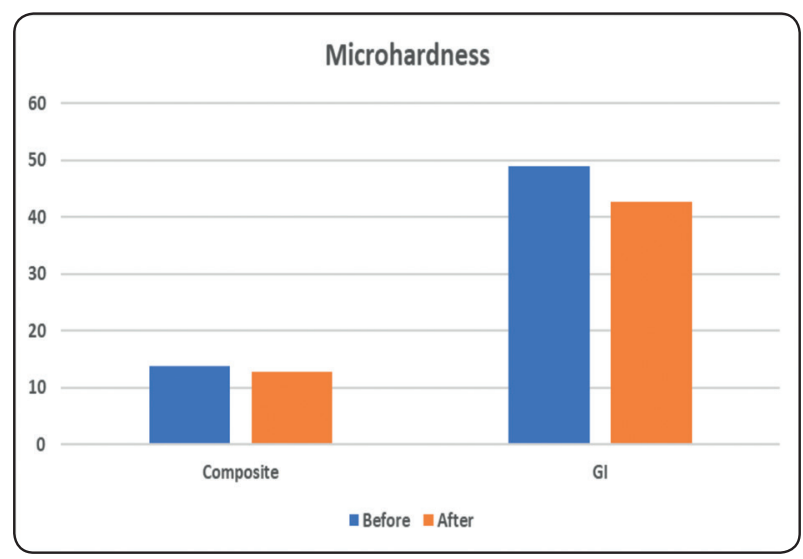

Fig. (3): Bar chart representing micro-hardness before and after bleaching procedures for the two tested groups

2) Comparing the percentage of change in micro-hardness of the tested restorative materials under the influence of the bleaching procedure:

A statistically significant difference was found between both tested restorative materials. (Table: 5 and fig:4). The highest mean value of the percentage of change was recorded in Ketac Universal Aplicap (mean $=6.16, \mathrm{SD}=1.82$ ), while the lowest mean 
value was found in Vertise Flow (mean $=1.09, \mathrm{SD}=$ $0.34)$ where $(\mathrm{p}<0.001)$.

TABLE (5): The mean, standard deviation (SD) of percentage of change of the microhardness in both tested groups under the influence of the bleaching procedure.

\begin{tabular}{|l|c|c|c|}
\hline \multirow{2}{*}{\multicolumn{1}{|c}{ Variables }} & \multicolumn{3}{|c|}{ Microhardness } \\
\cline { 2 - 4 } & Mean & SD & $\%$ \\
\hline Vertise Flow & 1.09 & 0.34 & $7.90 \%$ \\
\hline Ketac Universal Aplicap & 6.16 & 1.82 & $12.46 \%$ \\
\hline$p$-value & \multicolumn{4}{|c|}{$<\mathbf{0 . 0 0 1} *$} \\
\hline
\end{tabular}

*; significant $(p<0.05) \quad n s ;$ non-significant $(p>0.05)$

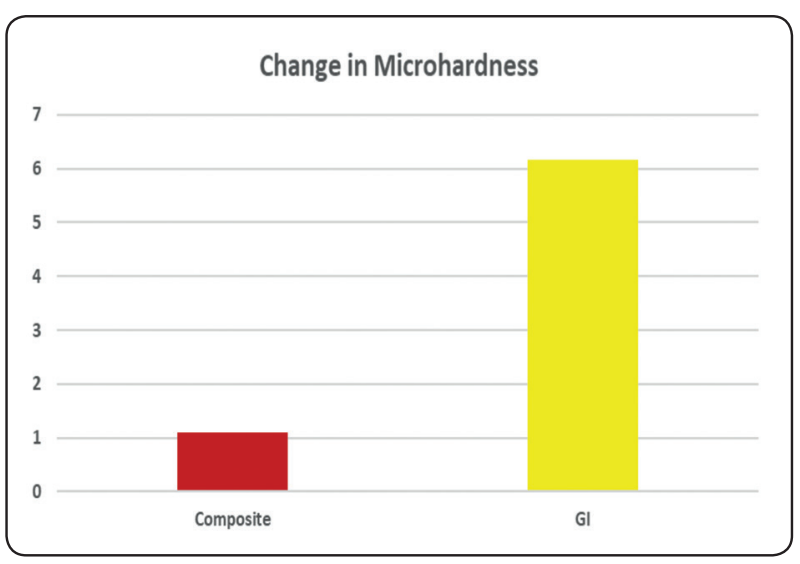

Fig. (4): Bar chart representing the mean change of percentage of the micro-hardness for both tested groups under the influence of the bleaching procedure.

\section{DISCUSSION}

Esthetics is now becoming one of the most popular concerns in the dental practice. The patient is seeking whiter teeth, brighter smile and more attractive looks, and the dentist must fulfill such demand. In response to such requirement; bleaching is becoming a more trendy procedure. However, as the bleaching agents are chemically active, rich in diffusible hydrogen peroxide; some restorative materials might be affected by the chemical ingredients in the bleaching gel (Polydorou et al, 2007), the free radicals might result in microcracks of the esthetic restorative materials and negatively affect its longevity (Hannig et al, 2007) (Malkondu 2011).

Recently introduced tooth colored restoratives one of them is conventional glass ionomer (GI) that is intended to be used without cavity preconditioning and without a protective coating is considered a privilege. It provides faster procedures that reduces clinical steps-yet still delivers physical and mechanical properties higher than other competitive glass ionomers which require a protective coating as claimed by the manufacturer (3M, ESPE, USA). Also, direct resin composite restorations are considered one of the most popular tooth colored materials. However, the bonding procedure could be a time consuming and a technique sensitive step for some clinicians. Therefore, some the manufacturers introduced a self-adhesive resin composite restorative material to simplify procedural steps (Frankenberger et al, 2000).

The bleaching process being a trendy service introduced in the dental office, should not alter the existing restorations in the oral cavity. Yet, changes in the surface texture, and micro-hardness may be controversial (Polydorou et al, 2007) (Wang et al, 2011). This study compared the newly introduced glass ionomer material to the self adhesive composite material, as both of them were marketed as simpler and easier tooth colored restorative alternatives, especially when exposed to the bleaching treatment challenge.

\section{The surface gloss}

The appearance of any restoration is mostly determined by how light interacts with the object curves and varied surface. Attractive restoration replacements start with a consistent outline and shape of the surface as the most important aspects of tooth/restoration matching is determined by how 
the majority of light will be reflected. (Fondriest, 2004). Furthermore, surface gloss originates from an uneven geometrical light distribution reflected by the surface and the gloss of any restorative material is reported to be considerably influenced by the surface roughness. It was stated that there was a correlation between the roughness and the inverse of the contrast gloss (O'Brien et al, 1984) (Lopes et al 2018). Therefore it could be of value to investigate the surface gloss of the tested materials after exposure to the bleaching procedure.

The current study results revealed that there was a significant decrease in the surface gloss of both tested materials after exposure to the bleaching agent; this could be due to a degradation influence and hydrolysis of the polymeric resin under the influence of the basic $\mathrm{pH}$ of the bleaching gel used which was equal to 7.9 (Cilli et al 2012)( Jamshidian et al, 2016). Furthermore, it was reported that esthetic restoratives with larger-size filler particles displayed higher surface roughness when compared to those containing nano-sized fillers.(Moraes et al, 2008), this goes in agreement with the results of the current study as expressed in terms of surface gloss, where the smaller and finer particles of the flowable resin material $(0.7-1 \mu \mathrm{m}$ average filler ) resulted in less space between the particles, and lower resin porosity compared to the glass ionomer tested (averages particles sizes $7.2 \mu \mathrm{m}$ ) (Abdelahmid et al 2018). This explains that despite the fact that both tested materials were subjected to deterioration under the influence of the bleaching gel applied, the outcome varied according to the compositional variation of each one of them. This was highly significant in the glass ionomer test group of the larger particle filler size and moreover expressed as the highest change in surface gloss percentage. Yet, this was contrary to Irawan etal, 2016, stated that there were no statistically significant changes in surface roughness of the tested G.I and resin composite, but this could be referred to that both tested materials were nano-filled.

\section{Micro-hardness}

Micro-hardness of the material depends on its type, composition and tendency to degrade over time. Conflicting outcome regarding the effects of bleaching on surface micro-hardness of restorative materials may be related to the composition, concentration and $\mathrm{pH}$ of the bleaching agent as well as to the application time. Also, the filler particles influence the physical and mechanical properties of the restorative material and might protect the organic matrix against the force applied to the direct restoration, having a direct influence on the surface properties of the restorative material (Hilton et al., 2013; Kaizer et al., 2014; Manhart et al., 2000; Rawls et al., 2013). It was concluded earlier that bleaching agents generally lead to softening and reduction of the surface micro-hardness (Taher et al, 2005). The same end result was found in the current study, where the application of the bleaching agent led to reduction in surface micro-hardness of both tested restorative materials. Also, an invitro study including a flowable composite, and a glass ionomer cement exposed to $40 \%$ hydrogen peroxide gel showed that both materials were found to experience surface softening (Yu et al, 2013).

Despite this study revealed that the initial mean value of the micro-hardness of the G.I was higher than flowable resin composite at the baseline; the percentage of change in the mean value of micro-hardness after exposure to bleaching was significantly higher in G.I (12.46\%) when compared to the flowable composite $(7.9 \%)$. This meant that G.I was dramatically influenced in a negative manner by such intervention (bleaching). A previous study showed that all glass ionomer restorative formulations exhibited a degree of dissolution (Bardoui et al, 2014). Glass ionomers contain filler particles which are surrounded by a hydrogel matrix which is permeable that it allows the bleaching gel to access to the subsurface layer of the material. After bleaching treatment rupture of primary bonds in the material leads to softening and plasticizing of the surface (Mair and Joiner, 2004). 
An explanation for the low micro-hardness of the flowable composite was that higher nanoparticle concentration might create uncontrollable agglomerates (Elsaka et al, 2011), moreover, the large number of nano particles joined together, leads to non-homogenous strengthening due to uneven distribution of the particles (Provotorov et al, 2010).

This current in-vitro study did not simulate some clinical circumstances; the effect of diluting saliva on the bleaching gel and other oral environmental factors. So, it is advised to simulate the influence of the oral conditions on the physical and optical properties of the esthetic restoratives when involved in a bleaching protocol. Furthermore, it could be of value to evaluate the effect of bleaching on the recently introduced G.I material when protective coating is applied regardless of the manufacturer claim.

\section{CONCLUSION}

Under the conditions of the present in vitro study, it can be concluded that the surface configuration and micro-hardness of both tested materials are negatively influenced when subjected to in-office bleaching.

\section{REFERENCES}

1. Abdel Hamid D, Mahmoud G El-Sharkawy F, Abou Auf E: Effect of surface protection, staining beverages and aging on the color stability and hardness of recently introduced uncoated glass ionomer restorative material. Future dental journal; (2018): 1-9

2. Baroudi K, Mahmoud R, Tatakji B, altamimi M: Effect of vital bleaching on disentigration tendency of glass ionomer restorations. Journal of clinical and diagnostic research; (2014): vol 8 (2):214-21

3. Canay S, and Cehreli M, "The effect of current bleaching agents on the color of light-polymerized composites in vitro," Journal of Prosthetic Dentistry; (2003): vol. 89, no. 5, pp. 474-478.

4. Cilli R, Pereira JC, Prakki A: Properties of dental resins submitted to $\mathrm{pH}$ catalysed hydrolysis. J Dent ; (2012): 40: 1144-1150.
5. Elsaka SE, Hamouda IM, Swain MV. Titanium dioxide nanoparticles addition to a conventional glass-ionomer restorative: Influence on physical and antibacterial properties. J Dent; (2011): 39(9): 589-98.

6. Frankenberger R., Kramer N., Petschelt A: Technique sensitivity of dentin bonding: effect of application mistakes on bond strength and marginal adaptation. Operative Dentistry; (2000): 25:324-330.

7. Fondriest J: Shade matching in restorative dentistry: the science and strategies .Int J Periodontics Restorative Dent; (2004): 23: 467-79.

8. Hannig C, Duong S, Becker K: Effect of bleaching on subsurface micro-hardness of composite and a polyacid modified composite. Dent Mater;(2007): 23: 198-203.

9. Hilton, T.J., Ferracane, J.L., Broome, J: Fundamentals of Operative Dentistry: A Contemporary Approach; (2013): Fourth Edition.

10. Jamshidian M, Rezvani MB, Snei M, Babasfari M, AminravianS. : Comparing the $\mathrm{pH}$ of different tooth whitening products related to their efficacy and safety. IJBPAS, March; (2016): 5(3): 632-641

11. Kaizer R., De Oliveira-Ogliari, A., Cenci S., Opdam M., Moraes R: Do nanofill or submicron composites show improved smoothness and gloss: a systematic review of in vitro studies. Dent. Mater; (2014): 30, e41-e78.

12. Lopes I, Monteiro P, Mendes J, Gonc,alves J, Caldeira F: The effect of different finishing and polishing techniques on surface roughness and gloss of two nanocomposites. Saudi Dental Journal ; (2018): 30, 197-207.

13. Mair L, Joiner A. The measurement of degradation and wear of three glass ionomers following peroxide bleaching. J Dent; (2004): 32:41-5.

14. Malkondu O, Yurdaguven H, Say EC, Kazazoğlu E, Soyman M: Effect of bleaching on microhardness of esthetic restorative materials. Oper Dent; (2011): 6: 177-186.

15. Manhart, J., Kunzelmann, K.H., Chen, H.Y., Hickel, R: Mechanical properties of new composite restorative materials. J. Biomed. Mater ; (2000): Res. 53, 353-361.

16. Moraes R, Ribeiro D, Klumb M, Brandt,Correr-Sobrinho L, Bueno M: In vitro tooth brushing abrasion of dental resin composites: packable, microhybrid, nanohybrid and microfilled materials. Braz Oral Res; (2008): 22: 112-118. 
17. Moraes RR, Gonçalves LS, Lancellotti AC, Consani S, Correr-Sobrinho L, Sinhoreti MA: Nanohybrid resin composites: nanofiller loaded materials or traditional microhybrid resins? Oper Dent; (2009): 34:551-557.

18. O'Brien WJ, Johnston WM, Fanian F, Lambert S: The surface roughness and gloss of composites. J Dent Res; (1984): 63: 685-688.

19. Polydorou O, Mönting JS, Hellwig E, Auschill TM: Effect of in-office tooth bleaching on the microhardness of six dental esthetic restorative materials. Dent Mater; ( 2007): 23: 153-158.

20. Provotorov M, Bobileva O. Nano sized modification of materials: Principles, examples, production, economy, COST Action Workshop MP0701, "Nanoparticles Surface (Modified/ Unmodified) as a base for the interaction with polymer matrix", September 23-24, (2010): Novi Sad, Serbia, Program and Book of Abstracts

21. Rawls, H.R., Shen, C., Anusavice, K.J: Phillip's science of dental materials. J. Chem. Inform; (2013) Model.

22. Rosentritt M, Lang R, Plein T, ,Behr M, Handel G: Discoloration of restorative materials after bleaching applica- tion. Quintessence International; (2005): vol. 36, no. 1, pp. 33-39.

23. Taher NM: The effect of bleaching agents on the surface hardness of tooth colored restorative materials. J Contemp Dent Pract; (2005): 15: 18-26.

24. Wang L, Francisconi LF, Atta MT, Dos Santos JR, Del Padre NC, Gonini A Jr, Fernandes KB: Effect of bleaching gels on surface roughness of nanofilled composite resins. Eur J Dent; (2011): 5: 173-179.

25. Yu H, Li Q, Hussain M, Wang Y: Effects of bleaching gels on the surface microhardness of tooth-colored restorative materials in situ. Journal of Dentistry; (2008): vol. 36,no. 4,pp. 261-267.

26. Yu H, Li Q, Wang Y, Cheng H: Effects of temperature and in-office bleaching agents on surface and subsurface properties of aesthetic restorative materials. J Dent; (2013): 41:1290-1296.

27. Xie H., Zhang F., Wu Y, Chen C., Liu W: Dentin bond strength and microleakage of flowable composite, compomer and glass ionomer cement. Australian Dental Journal; (2008): 53 (4): 325-331. 